University of Wollongong

Research Online

Faculty of Engineering and Information

Faculty of Engineering and Information

Sciences - Papers: Part A

Sciences

2004

Effect of aging and deformation on the microstructure and properties of Fe$\mathrm{Ni}$-Ti maraging steel

A Shekhter

Defence Science and Technology Organization

H I. Aaronson

Monash University

M K. Miller

Oak Ridge National Laboratory

S P. Ringer

University of Sydney

E V. Pereloma

University of Wollongong, elenap@uow.edu.au

Follow this and additional works at: https://ro.uow.edu.au/eispapers

Part of the Engineering Commons, and the Science and Technology Studies Commons

Research Online is the open access institutional repository for the University of Wollongong. For further information contact the UOW Library: research-pubs@uow.edu.au 


\title{
Effect of aging and deformation on the microstructure and properties of Fe-Ni-Ti maraging steel
}

\author{
Abstract \\ The age-hardening behavior of Fe-25.3Ni-1.7 Ti (wt pct) alloy both in undeformed specimens and in \\ specimens cold deformed by 10 or 20 pct prior to aging was studied. The microstructural changes during \\ aging were observed using transmission electron microscopy (TEM) and atom probe analysis and there \\ were related to the mechanical properties as measured by microhardness and shear punch testing. An \\ excellent combination of hardness, strength, and ductility was achieved after only 5 seconds aging at \\ $550^{\circ} \mathrm{C}$. We propose that this rapid strengthening is due to a dislocation friction effect arising from the \\ formation of a fine dispersion of $\mathrm{Ni}-\mathrm{Ti}$ atomic co-clusters during this short aging time. The concomitant \\ effects of a reverse transformation of martensite to austenite during aging and a gradual increase in both \\ size of the clusters and distance between them contributed to a decrease in strength after aging for 15 \\ seconds. This decline proceeded until aging for 300 seconds and was followed by a secondary hardening \\ reaction toward peak hardness (at 10,800 seconds) and subsequent overaging. This secondary hardening \\ was associated with fine-scale precipitation of $\mathrm{Ni}_{3} \mathrm{Ti}$ and this process was accelerated by deformation \\ prior to aging, leading to a reduction or elimination of hardness decline after the initial cluster hardening.

\section{Keywords} \\ maraging, ti, ni, fe, aging, properties, steel, effect, deformation, microstructure

\section{Disciplines} \\ Engineering | Science and Technology Studies

\section{Publication Details} \\ Shekhter, A., Aaronson, H. I., Miller, M. K., Ringer, S. P. \& Pereloma, E. V. 2004, 'Effect of aging and \\ deformation on the microstructure and properties of Fe-Ni-Ti maraging steel', Metallurgical and Materials \\ Transactions A - Physical Metallurgy and Materials Science, vol. 35, no. 13, pp. 973-983.
}




\title{
Effect of Aging and Deformation on the Microstructure and Properties of Fe-Ni-Ti Maraging Steel
}

\author{
A. SHEKHTER, H.I. AARONSON, M.K. MILLER, S.P. RINGER, and E.V. PERELOMA
}

\begin{abstract}
The age-hardening behavior of Fe-25.3Ni-1.7 Ti (wt pct) alloy both in undeformed specimens and in specimens cold deformed by 10 or 20 pct prior to aging was studied. The microstructural changes during aging were observed using transmission electron microscopy (TEM) and atom probe analysis and there were related to the mechanical properties as measured by microhardness and shear punch testing. An excellent combination of hardness, strength, and ductility was achieved after only 5 seconds aging at $550{ }^{\circ} \mathrm{C}$. We propose that this rapid strengthening is due to a dislocation friction effect arising from the formation of a fine dispersion of $\mathrm{Ni}-\mathrm{Ti}$ atomic co-clusters during this short aging time. The concomitant effects of a reverse transformation of martensite to austenite during aging and a gradual increase in both size of the clusters and distance between them contributed to a decrease in strength after aging for 15 seconds. This decline proceeded until aging for 300 seconds and was followed by a secondary hardening reaction toward peak hardness (at 10,800 seconds) and subsequent overaging. This secondary hardening was associated with fine-scale precipitation of $\mathrm{Ni}_{3} \mathrm{Ti}$ and this process was accelerated by deformation prior to aging, leading to a reduction or elimination of hardness decline after the initial cluster hardening.
\end{abstract}

\section{INTRODUCTION}

MARAGING steels are low-carbon martensitic steels developed in the 1960s for applications requiring ultra-high strength combined with good fracture toughness. ${ }^{[1]}$ These steels are used for heavy-duty structural applications after quenching and aging. Such properties are obtained by the precipitation of intermetallic phases in the martensite matrix. ${ }^{[2]}$ The morphology and crystal structure of the precipitates depend on the composition of the alloy, aging temperature, and time. Typically, these steels are solution treated in the fully austenitic $(\gamma)$ region $\left(\geq 900^{\circ} \mathrm{C}\right)$, quenched to produce a completely martensitic $\left(\alpha^{\prime}\right)$ matrix, and then aged at temperatures within the range $400{ }^{\circ} \mathrm{C}$ to $600{ }^{\circ} \mathrm{C}$.

Although the precipitation process and the character of the precipitates in maraging steels with various compositions have been studied extensively, ${ }^{[1-7]}$ details of their character and the strengthening mechanisms remain incomplete. Most of the work to date has involved isothermal aging for times of 180 seconds or greater ${ }^{\left[{ }^{[11]}\right.}$ However, indications of substantial strengthening taking place at earlier times have been reported in studies involving continuous heating. ${ }^{[3,4]}$ In all

A. SHEKHTER, formerly Research Associate, School of Physics and Materials Engineering, Monash University, Victoria, 3800, Australia, is Research Scientist, Defence Science and Technology Organization (DSTO), Melbourne, Victoria, 3001, Australia. H.I. AARONSON, R.F. Mehl University Professor Emeritus, Department of Materials Science and Engineering, Carnegie Mellon University, Pittsburgh, PA, 15213, is also Visiting Professor, School of Physics and Materials Engineering, Monash University. M.R. MILLER, Distinguished R\&D Staff Member, is with the Microscopy, Microanalysis, Microstructures Group, Metals and Ceramics Division, Oak Ridge National Laboratory, Oak Ridge, TN 37831-6136. S.P. RINGER, Associate Professor and Director, is with the Australian Key Centre for Microscopy \& Microanalysis, The University of Sydney, 2006, NSW, Australia. E.V. PERELOMA, Senior Lecturer, is with the School of Physics and Materials Engineering, Monash University. Contact e-mail: elena.pereloma@spme.edu.au

Manuscript submitted January 6, 2003. cases of maraging alloys containing $\mathrm{Ni}, \mathrm{Cr}$, Mo, Ti or $\mathrm{Ni}$, $\mathrm{Mn}, \mathrm{Ti}$, hardening has been associated with precipitation of

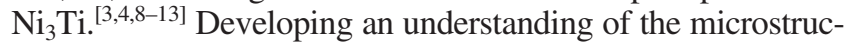
tural evolution and strengthening processes, particularly during the early stages of aging at a low homologous temperature, is a central theme of this work.

Observations of $\mathrm{Ni}_{3} \mathrm{Ti}$ precipitation have been made in Fe-25.67 wt pet Ni-1.68 wt pet Ti alloy by Garwood and Jones $^{[12]}$ and Pitler and Ansell. ${ }^{[13]}$ The $\eta \mathrm{Ni}_{3} \mathrm{Ti}$ precipitates, found in all maraging alloys, have a $\mathrm{DO}_{24}$ structure $(a=0.5093, c=0.8306 \mathrm{~nm})$ with an hep lattice and a needlelike morphology. ${ }^{[1-4,8-14]}$ The orientation relationship between $\mathrm{Ni}_{3} \mathrm{Ti}$ precipitate and martensite was found to be that of Burgers: ${ }^{[9]}$

$$
\begin{gathered}
\{1 \overline{1} 1\}_{\alpha^{\prime}} / /\{11 \overline{2} 0\}_{\mathrm{Ni}_{3} \mathrm{Ti}} \\
<011>_{\alpha^{\prime}} / /<0001>_{\mathrm{Ni}_{3} \mathrm{Ti}}
\end{gathered}
$$

The Garwood-Jones ${ }^{[12]}$ study was made on specimens aged at a homologous temperature of only 0.43 , where volume diffusivities should be very low. Such rapid hardening has also been observed in Al-base alloys and has been shown experimentally, by means of the three-dimensional atom probe (3DAP), to result from solid solution clustering (e.g., Reference 15). Clustering in Al-base alloys can take place at homologous temperatures as little as 0.33 , ${ }^{[16]}$ despite the generally lower diffusivities at comparable homologous temperatures in fcc than in bcc alloys. ${ }^{[17]}$ However, quenched-in vacancies clearly expedite clustering in $\mathrm{Al}$ alloys. ${ }^{[15]}$ While the matrix in maraging steels is highly dislocated and so quenched-in vacancies are unlikely to play any role, the potential for effects from precipitate solute clusters is high. We have thought to ascertain the mechanism through which rapid hardening is achieved in maraging steels, from a technological as well as a fundamental context. An additional purpose of this investigation is to examine the effects of plastic deformation upon the various aging processes. 


\section{EXPERIMENTAL METHODS AND TECHNIQUES}

Small ingots of an Fe-25.3 wt pet Ni-1.7 wt pct Ti alloy, whose detailed chemical analysis is given in Table I, were produced from high-purity materials at the Institute for Metal Physics, National Academy of Sciences, Ukraine. These ingots were homogenized at $1150{ }^{\circ} \mathrm{C}$ for 15 hours. Slices of homogenized samples, 0.35 - to $0.4-\mathrm{mm}$ thick, were cut for heat treatment so as to provide shear punch test specimens and transmission electron microscopy (TEM) foils. They were immersed in alumina powder and solution treated at $1050{ }^{\circ} \mathrm{C}$ for 3600 seconds, cold water quenched, and then transferred to liquid nitrogen to produce an almost entirely martensitic matrix. The slices were then aged at $550{ }^{\circ} \mathrm{C}$ in a salt bath for $5,10,15,30,45,60,300,180,600,3600$, $10,800,36,000$, and 86,400 seconds.

In order to observe the effect of plastic deformation on the age-hardening process, some samples of the alloy were deformed immediately after liquid nitrogen cooling, prior to isothermal aging at $550{ }^{\circ} \mathrm{C}$. These samples were deformed by cold rolling reductions of approximately 10 and $20 \mathrm{pct}$ of the original thickness. The samples were polished and the thickness of each sample was measured at three points to ensure that the two surfaces on which rolling force was applied were parallel. The difference in thickness of the samples prior to and following the deformation was used to determine the amount of deformation. Microhardness of all specimens was measured using a Matsuzawa microhardness tester under a $0.2-\mathrm{kg}$ load. Six to eight measurements were taken on each sample and then averaged. Normalized dislocation density was calculated according to the method of Dieter $^{[18]}$ using the microhardness data on as-quenched undeformed, 10 pct, and 20 pct deformed conditions.

Following heat treatment, slices of steel were ground to a thickness of $0.3 \mathrm{~mm}$ for shear punch testing. Shear punch testing (SPT) was developed by Lucas et al. ${ }^{[19]}$ to improve the sensitivity to microstructure when testing small volumes of material and to allow the determination of tensile properties from miniature specimens. An SPT rig was manufactured in-house and attached to an Instron 4500 tensile tester. A $5-\mathrm{kN}$ load cell with a crosshead speed of $0.25 \mathrm{~mm} / \mathrm{min}$ and a 3-mm-diameter punch was used in the tests. The test was instrumented to provide punch load-displacement data so as to determine effective tensile strength using the following empirical equation: ${ }^{[19]}$

$$
\sigma_{\text {eff }}=\frac{P-F}{2 \pi r t}=C \sigma
$$

where $P=$ load $(\mathrm{N}), \sigma=$ corresponding uniaxial stress (MPa), $F=$ friction load $(\mathrm{N}), r=$ punch radius $(\mathrm{mm}), t=$ specimen thickness (mm), and $C$ is an empirical correlation coefficient. This coefficient relates the shear punch load-displacement curves to uniaxial tensile data and has been found to equal
0.54 for the yield strength (YS) and 0.62 for the ultimate tensile strength (UTS) in this class of materials. ${ }^{[19]}$

The percentage reduction in area (Pct RA) was used to assess ductility and was determined using the following equation:

$$
\text { Pct RA }=d_{f} / t
$$

where $t$ is specimen thickness and $d_{f}$ is displacement at failure.

Thin foils for TEM were prepared by twin jet polishing using 5 pct perchloric acid in methanol at $-30{ }^{\circ} \mathrm{C}$. They were examined in a PHILIPS* CM20 transmission electron

*PHILIPS is a trademark of Philips Electronic Instruments Corp., Mahwah, NJ.

microscope operating at accelerating voltage of $200 \mathrm{kV}$. Selected samples were analyzed using a high-resolution transmission electron microscope (HRTEM) JEOL**30 00F oper-

**JEOL is a trademark of Japan Electron Optics Ltd., Tokyo.

ating at $300 \mathrm{kV}$. Samples for the HRTEM were prepared so as to minimize the volume of magnetic material inserted within the column. A combination tripod and ion milling method was used.

In order to validate statistically the dimensional differences of $\mathrm{Ni}_{3} \mathrm{Ti}$ precipitates at various aging times for the three conditions (undeformed, $10 \mathrm{pct}$, and 20 pct cold rolled), the average size of $\mathrm{Ni}_{3} \mathrm{Ti}$ particles was measured as projected in a $\{001\}_{\alpha^{\prime}}$ matrix plane.

Three-dimensional atom probe analysis was undertaken to assess the extent of solute-solute interactions in undeformed samples in the as-quenched condition and after aging for 5 and 15 seconds. Samples for 3DAP analysis were electropolished first in 25 pct perchloric acid in acetic acid with a DC voltage of 5 to $10 \mathrm{~V}$. Specimens were then observed under an optical microscope at 50 times magnification to examine the shape of the tip and its suitability for 3DAP analysis. Some tips were further sharpened in a solution of 5 pct perchloric acid in 2-butoxyethanol using a DC voltage of $\sim 10 \mathrm{~V}$.

The volume fraction of retained austenite was measured using a PHILIPS PW 1130 X-ray diffractometer (XRD) with $\mathrm{Cu} K_{\alpha}$ radiation $(40 \mathrm{kV}, 30 \mathrm{~mA})$. The integrated intensities of the $(200)_{\alpha},(211)_{\alpha}$, and $(200)_{\gamma}$ peaks were used in the direct comparison method. ${ }^{[20]}$

\section{RESULTS}

\section{A. Mechanical Properties}

Age-hardening curves for alloy samples aged after 0 pct (undeformed), 10 pct, and 20 pct deformation are presented in Figure 1. The undeformed material exhibits an initial hardening response at 5 seconds followed by a continuous decrease in hardness between 10 and 600 seconds of isothermal aging.

Table I. Composition of Maraging Steel Investigated

\begin{tabular}{lccccccccccc}
\hline \multicolumn{10}{c}{ Chemical Composition (Wt Pct) } \\
\hline $\mathrm{C}$ & $\mathrm{Mn}$ & $\mathrm{Si}$ & $\mathrm{Ni}$ & $\mathrm{Cr}$ & $\mathrm{Mo}$ & $\mathrm{Cu}$ & $\mathrm{Ti}$ & $\mathrm{Al}$ & $\mathrm{P}$ & $\mathrm{S}$ \\
$<0.01$ & 0.02 & $<0.02$ & 25.3 & $<0.1$ & $<0.01$ & 0.1 & 1.7 & 0.1 & 0.01 & 0.01 \\
\hline
\end{tabular}




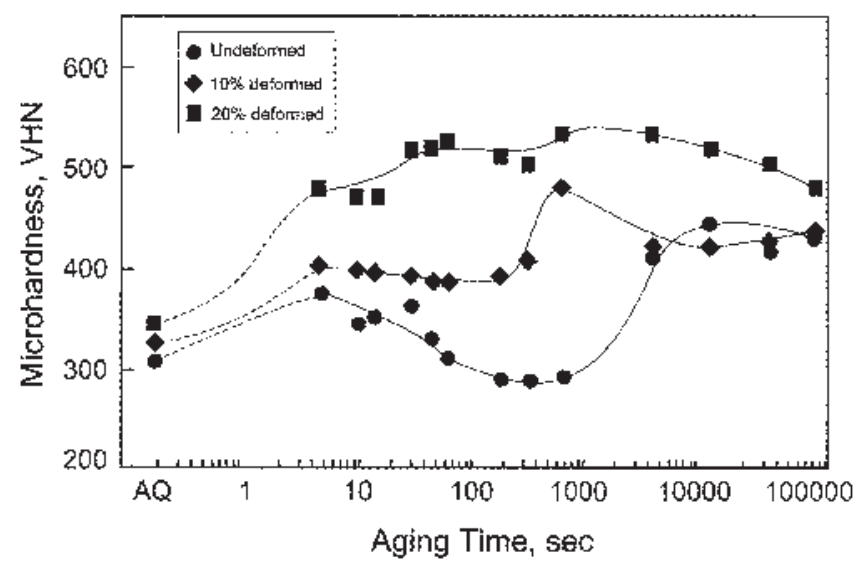

Fig. 1-Age-hardening response of Fe-Ni-Ti alloy in the undeformed, $10 \mathrm{pct}$, and 20 pct deformed conditions.

This is followed by a secondary hardening reaction toward peak hardness at 10,800 seconds. The age-hardening plots for the 10 and 20 pct deformed material exhibit similar initial hardening trends. After 10 pct deformation, however, there is only a minimal decrease in hardening. Following rapid initial hardening after 5 seconds of aging, a near-plateau hardness level is maintained for the next $\sim 300$ seconds before a secondary hardening toward a peak value at $\sim 600$ seconds and subsequent overaging. For samples aged after $20 \mathrm{pct}$ deformation, the rapid initial hardening was followed by a relatively short hardness plateau. A further increase in hardness is followed by a longer plateau. Aging times beyond 3600 seconds resulted in a continuous decrease in hardness.

Figures 2(a), (b), and (c) present the variation with aging time of the effective UTS, effective YS, and RA for samples aged at $550{ }^{\circ} \mathrm{C}$ after 0 (undeformed), 10, and $20 \mathrm{pct}$ deformation, respectively. The data on the undeformed condition (Figures 2(a) and (b)) demonstrates a modest initial rise in both UTS and YS. Both properties pass through a maximum at similar aging times, decline, and then slowly increase again. Although both of these curves are broadly similar to that for microhardness (Figure 1), the initial rise in hardness appears to occur much more rapidly and at a much earlier time (5 seconds $v s 60$ seconds) than the corresponding increases in UTS and YS. Similarly, the subsequent decrease in hardness is more pronounced than in the two tensile properties. Both hardness and UTS showed secondary maxima followed by a slow decline.

For samples aged after 10 pct deformation, both the UTS and YS curves follow the same trends as for microhardness. The UTS decreases before once again increasing toward a maximum of $1043 \mathrm{MPa}$ at 600 seconds (peak hardness). These trends are a significant indication of the aging process because the 95 pct confidence interval on the predicted UTS values was $\sim \pm 7$ pct. Both UTS and YS decrease more steeply after aging for longer times in comparison to undeformed specimens.

For samples aged after 20 pct deformation, microhardness, UTS, and YS also show similar trends, with the exception of a pronounced minimum in UTS. Both 10 and $20 \mathrm{pct}$ deformed alloys exhibit a decrease in UTS after 10 seconds of aging. As with the undeformed UTS and YS behavior, the 20 pct deformed material continues to strengthen up to

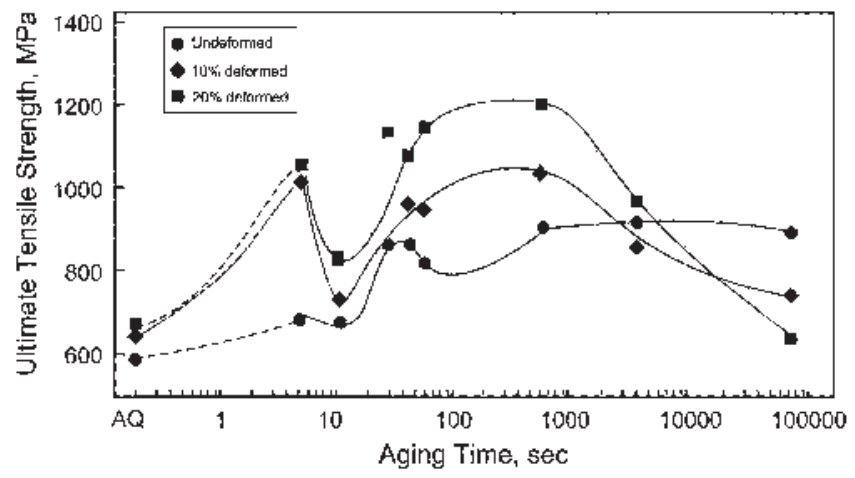

(a)

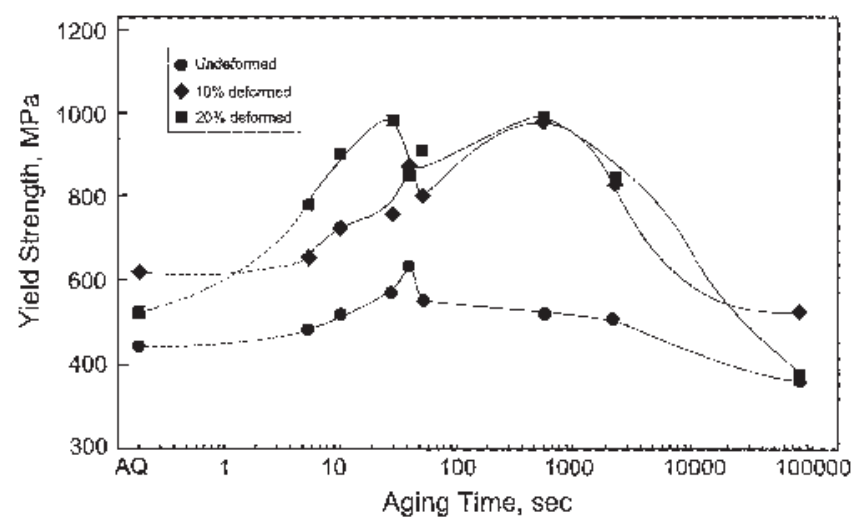

(b)

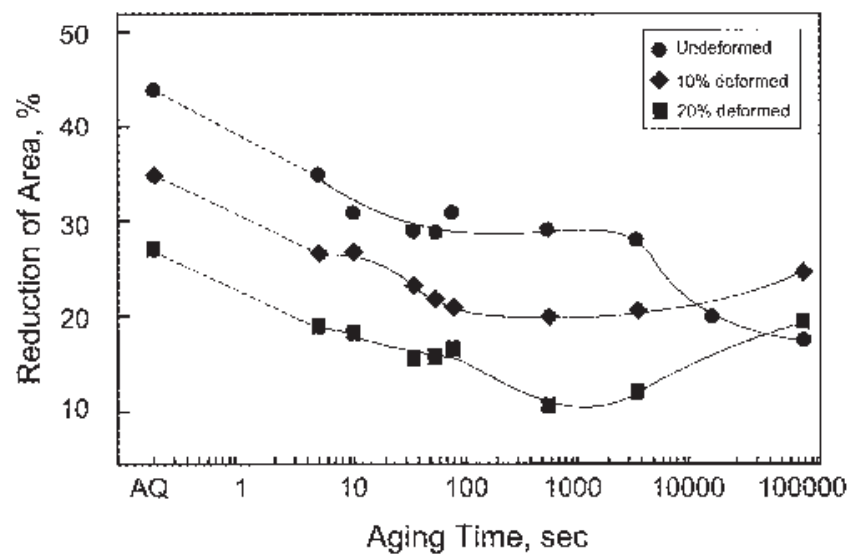

(c)

Fig. 2-(a) UTS, (b) YS, and (c) RA as a function of aging time for samples deformed, 0,10 , and 20 pct prior to aging.

600 seconds of aging time before softening commences. The decline is more pronounced in both UTS and YS than in microhardness.

In all samples (both undeformed and deformed prior to aging), the increase in hardness, UTS, and YS was accompanied by a corresponding decrease in ductility as measured by area reduction. The pct RA of undeformed as-quenched samples was 43 pct, while it was 36 and 28 pct in samples deformed 10 and 20 pet after quenching, respectively. After 5 seconds of aging, which is associated with the initial hardening, the pct RA decreased to 32,28 , and 18 pct in undeformed, $10 \mathrm{pct}$, and 20 pct deformed specimens, respectively. At peak hardness 
(which occurred after aging for 10,800 seconds in undeformed samples and after 600 seconds in deformed specimens), the pct RA decreased further to 18 pct in undeformed, 19 pct in 10 pct deformed, and 10 pct in 20 pct deformed specimens. Aging of deformed specimens for prolonged times (beyond the peak hardness and peak strength) showed a slight increase in pet RA values (Figure 2(c)).

\section{B. Microstructural Characterisation}

Microstructures of as-quenched materials are provided in Figure 3. The bright-field (BF) TEM images and corresponding selected area electron diffraction (SAED) inserts in Figures 3(a) and (b) indicate that the as-quenched microstructure in both the undeformed (Figure 3(a)) and deformed 20 pct (Figure 3(b)) conditions consisted predominantly of lath martensite with a high dislocation density, with some laths containing fine twins. Retained austenite films and blocks between the martensite crystals are indicated by arrows. The $\mathrm{X}$-ray analysis indicates that $\sim 2 \mathrm{vol}$ pct of retained austenite

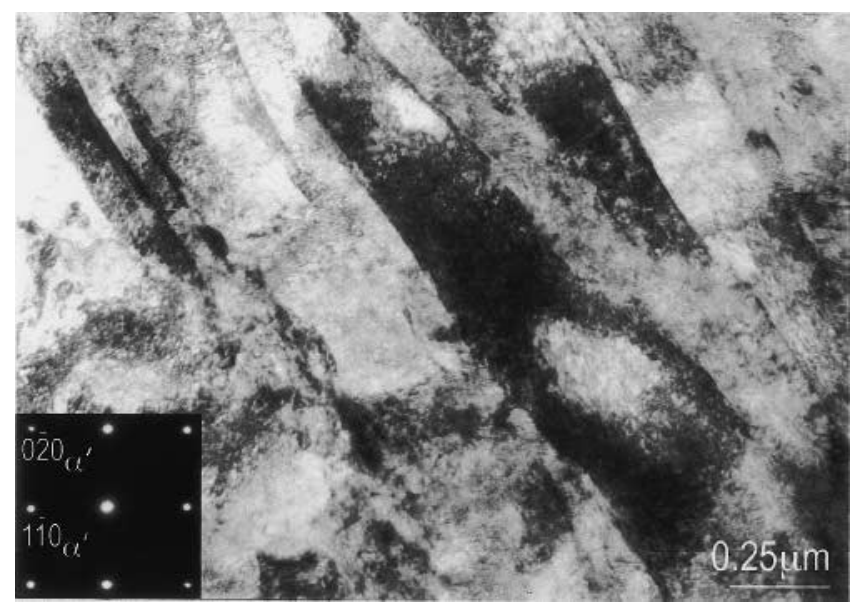

(a)

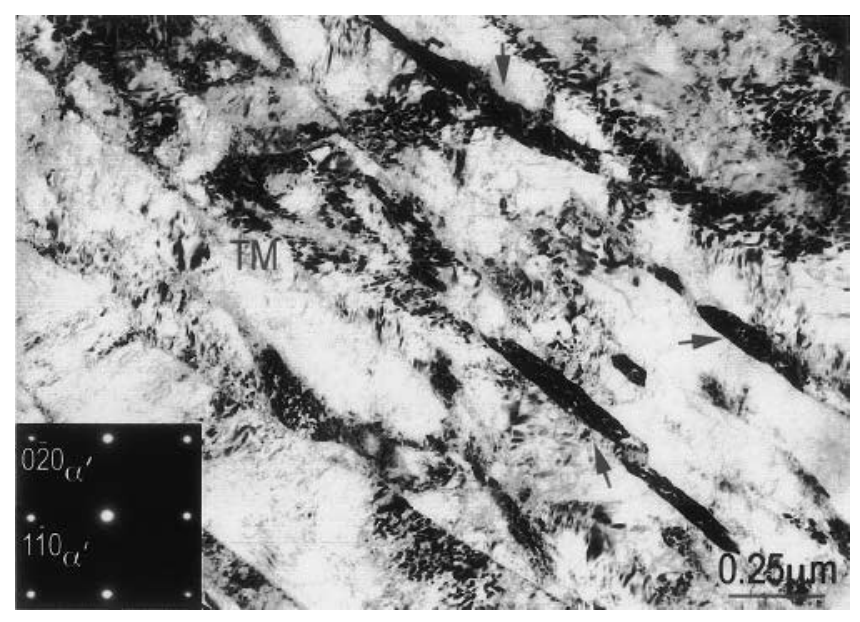

(b)

Fig. 3-Thin foil TEM of Fe-Ni-Ti alloy. (a) BF image of as-quenched undeformed sample with corresponding $[001]_{\alpha^{\prime}}$ SAED pattern. (b) $[001]_{\alpha^{\prime}}$ BF image and SAED pattern (inset) of the sample deformed 20 pct after quenching. Arrows indicate retained austenite films. TM denotes fine twinned martensite. was present in the microstructure before aging in both undeformed and deformed conditions. The 20 pct deformed samples appear to have a slightly increased dislocation density. The normalized stored dislocation density ${ }^{[18]}$ in samples aged after 10 and 20 pct deformation was 0.14 and 1 , respectively.

Figure 4 is a series of TEM micrographs recorded from undeformed specimens aged at $550{ }^{\circ} \mathrm{C}$ for times ranging from 5 to 3600 seconds. Figure 4(a) is the BF image from the sample aged for 5 seconds. The inset SAED pattern demonstrates that the matrix is precipitate free. Careful inspection of this microstructure was made using a HRTEM to search for regions having different periodicity or contrast. Both $\langle 100\rangle_{\alpha^{\prime}}$ and $\langle 111\rangle_{\alpha^{\prime}}$ orientations were used for this purpose. Figure $4(\mathrm{~b})$ provides a typical result. This work confirmed that no discrete second phase was present.

Figure 4(c) is a dark-field (DF) TEM image taken from near the $[001]_{\alpha^{\prime}}$ zone of the undeformed sample, aged for 45 seconds. The presence of precipitates in undeformed specimens was first observed at this aging time. From indexing of the diffraction pattern (Figure 4(d)), the precipitates were found to be $\eta\left(\mathrm{Ni}_{3} \mathrm{Ti}\right)$, having the previously reported $\mathrm{DO}_{24}$ structure $(a=0.5093, c=0.8306 \mathrm{~nm})$ with an hcp lattice..$^{[1-4]}$ The $\eta$ phase is related to the matrix by the Burgers orientation relationships between bcc and hcp lattices. ${ }^{[4]}$ Figure 4(d) also shows that there are reflections from two orientations of precipitates with the orientation relationship $[1 \overline{2} 10]_{\eta} \|[001]_{\alpha^{\prime}}$; this is consistent with the Burgers orientation relationship. The fine precipitates observed in Figure 4(c), having an average length of $10 \mathrm{~nm}$ and average interparticle distance of $17 \mathrm{~nm}$, are an example of one of these sets. These parameters remain little changed for aging times up to 60 seconds (Table II). After aging for 600 seconds, the average length of these needles has increased to $18.5 \mathrm{~nm}$, but is accompanied by an increase in the average distance between them to $19 \mathrm{~nm}$. The DF image in Figure 4(f) is recorded from a sample aged for 3600 seconds and shows evidence of a binominal distribution in precipitate size: coarse $\mathrm{Ni}_{3} \mathrm{Ti}$ precipitates located far from each other and needle-shaped finely dispersed $\mathrm{Ni}_{3} \mathrm{Ti}$ precipitates between them. It was observed that the coarse precipitates exhibited two morphologies (Figure 5(a)): very long needles, which preserved their original shape, and coarse plates. The fine needle-shaped precipitates were found to have the shortest interparticle spacing among interparticle distances measured after all aging times. Figure 5(b) is a DF TEM micrograph in which large, well-separated $\mathrm{Ni}_{3} \mathrm{Ti}$ precipitates and a dense dispersion of much smaller $\mathrm{Ni}_{3} \mathrm{Ti}$ precipitates are clearly seen.

A set of DF micrographs recorded from samples aged at $550{ }^{\circ} \mathrm{C}$ for various times after an initial 20 pct deformation following quenching is provided in Figure 6. As with the undeformed material, TEM of the sample after 5 seconds of aging time (Figure 6(a)) revealed no evidence of precipitation. However, the first $\mathrm{Ni}_{3} \mathrm{Ti}$ precipitates were observed soon after in the aging sequence: following 10 seconds at $550{ }^{\circ} \mathrm{C}$ (Figure 6(b)). This compares to the undeformed samples, where precipitation was not detected until 45 seconds of aging. The coarsening of precipitates from $6-\mathrm{nm}$ average length after 10 seconds of aging to 76-nm average length after 3600 seconds is observed clearly (Figure 6(f)). It is accompanied by a corresponding increase in interparticle distance from $\sim 7$ to $\sim 27 \mathrm{~nm}$ (Table II). The size and dis- 


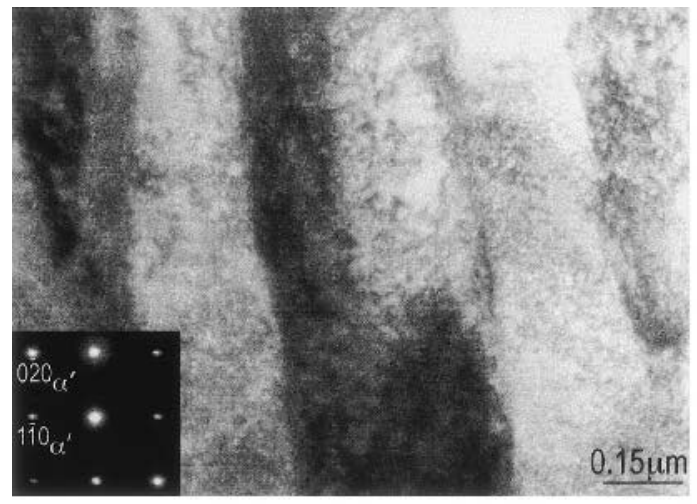

(a)

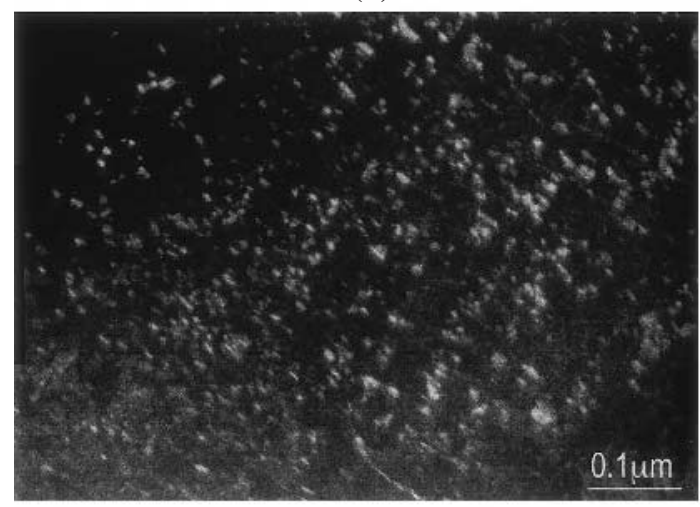

(c)

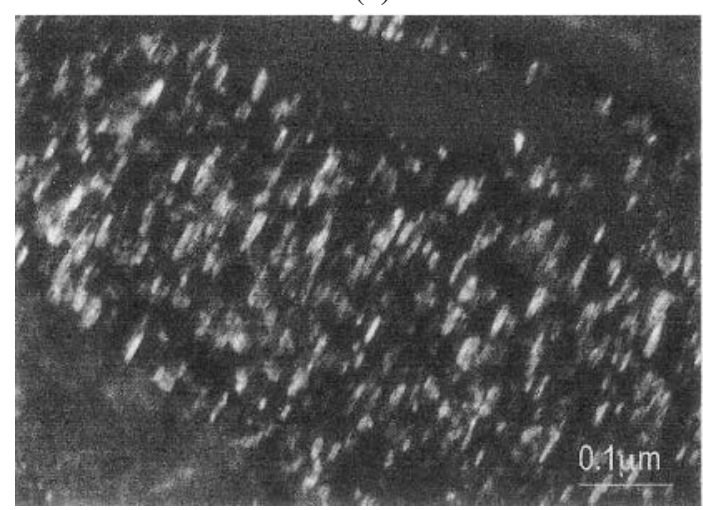

(e)

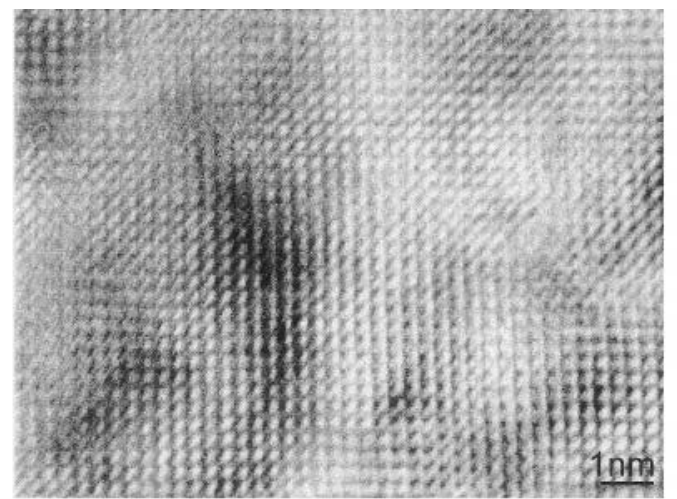

(b)

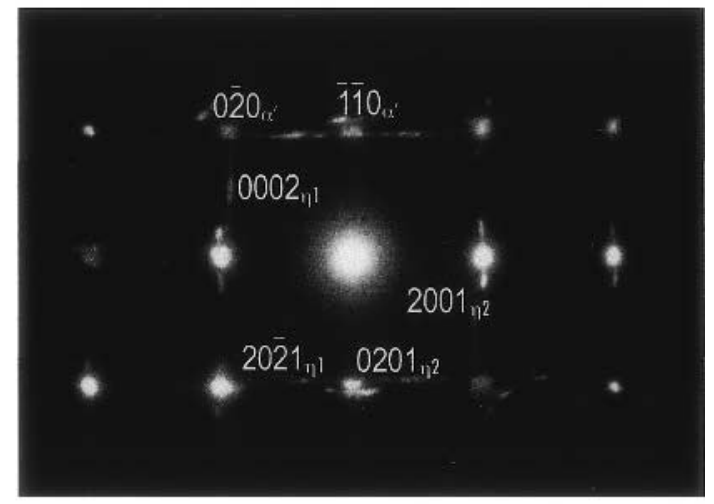

(d)

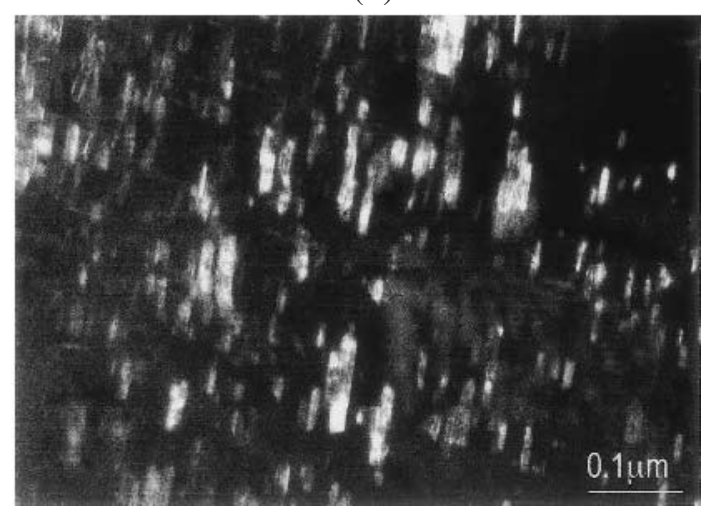

(f)

Fig. 4-Thin foil TEM of age-hardened undeformed Fe-Ni-Ti alloy aged at $550{ }^{\circ} \mathrm{C}$. Zone axis for (a) and (c) through (f) images is $[001]_{\alpha^{\prime}}$ : (a) BF image and SAED inset after $5 \mathrm{~s}$ of aging; (b) HRTEM image along [100] $]_{\alpha^{\prime}}$ from material aged for $5 \mathrm{~s} ;(c)$ DF image from a specimen aged for $45 \mathrm{~s}$ revealing one set of fine precipitates; $(d)$ typical SAED near $\mathbf{g}(0001)_{\eta} / /[001]_{\alpha^{\prime}}$. The reflections marked $\eta_{1}$ and $\eta_{2}$ represent two orientations of Ni $\mathrm{Ti}_{3}$ particles; $(e) \mathrm{DF}$ image after $600 \mathrm{~s}$ of aging; and $(f)$ DF image of the sample aged for $3600 \mathrm{~s}$.

tribution of coarse and fine $\mathrm{Ni}_{3} \mathrm{Ti}$ precipitates after $3600 \mathrm{sec}-$ onds aging was similar to the undeformed material.

The TEM examination of samples aged after an initial 10 pct deformation showed that they follow the same stages of microstructural evolution as the 20 pct deformed specimens. Very fine needle-shaped $\mathrm{Ni}_{3} \mathrm{Ti}$ precipitates of length $\sim 5.3 \mathrm{~nm}$ were observed in the microstructure after aging for 10 seconds. Peak hardness at 600 seconds corresponds to an average particle length of $21.5 \mathrm{~nm}$ with an average interparticle spacing of $\sim 20 \mathrm{~nm}$ (Figure 7). Two orientations of the $\mathrm{Ni}_{3} \mathrm{Ti}$ precipitates in martensite crystal are observed. Austenite crystals were also highlighted in this DF image (Figure $7(b))$, where the $\{220\}_{\gamma}$ reflection coincides nearly with the $\{22 \overline{4} 0\}_{\eta}$.
Figure 8 is a plot of the logarithm of the needle length as a function of the logarithm of aging time. The slope of the plot for undeformed specimens was 0.41 , whereas those for the 10 and 20 pct deformed specimens were 0.39 and 0.38 , respectively.

The X-ray diffraction analysis indicated a progressive increase in the volume fraction of austenite during aging from $\sim 2$ pct in both the as-quenched condition and after aging for 5 seconds through to $7,17,28,40$, and 55 pct after $15,60,600,3600$, and 86,400 seconds of aging, respectively (Table III). Similar trends (and values) were observed in the samples deformed 10 and 20 pct prior to aging. This is a result of transformation of martensite to austenite during isothermal aging at $550{ }^{\circ} \mathrm{C}$. 
Table II. Variation in Average Interparticle Distance and Particle Aspect Ratio with Aging Time

\begin{tabular}{|c|c|c|c|c|}
\hline \multirow[b]{2}{*}{$\begin{array}{l}\text { Aging } \\
\text { Time }\end{array}$} & \multicolumn{2}{|c|}{ Undeformed } & \multicolumn{2}{|c|}{20 Pct Deformed } \\
\hline & $\begin{array}{c}\text { Distance } \\
(\mathrm{nm})\end{array}$ & Ratio & $\begin{array}{l}\text { Distance } \\
(\mathrm{nm})\end{array}$ & Ratio \\
\hline $10 \mathrm{sec}$ & & & 7 & 0.08 \\
\hline $30 \mathrm{sec}$ & & & 9 & 0.08 \\
\hline $45 \mathrm{sec}$ & 17 & 0.12 & 13 & 0.12 \\
\hline $60 \mathrm{sec}$ & 17 & 0.14 & 15 & 0.2 \\
\hline $600 \mathrm{sec}$ & 19 & 0.22 & 22 & 0.28 \\
\hline \multicolumn{5}{|l|}{$3600 \mathrm{sec}$} \\
\hline Coarse precipitates & 23 & $0.26(0.16)^{*}$ & 27 & 0.16 \\
\hline Fine precipitates & 3 & 0.16 & 1.7 & 0.12 \\
\hline
\end{tabular}

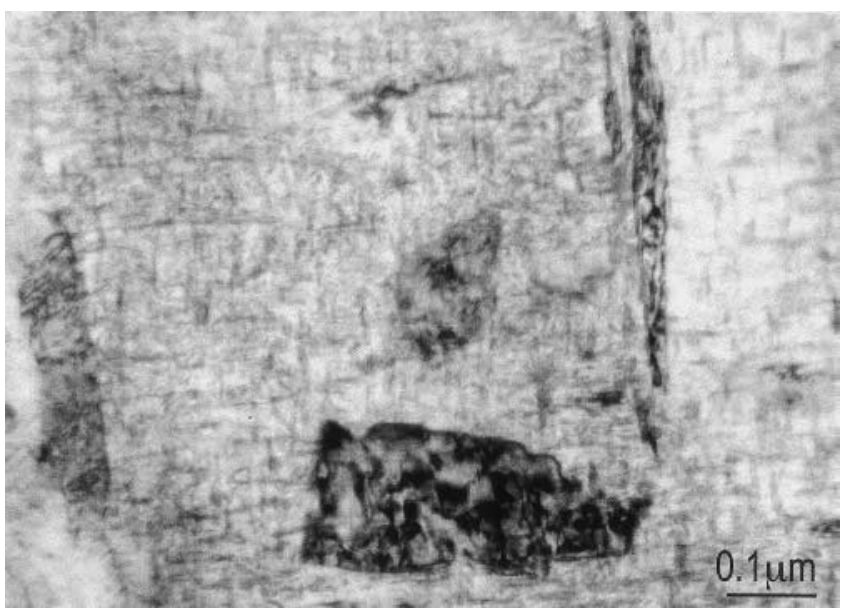

(a)

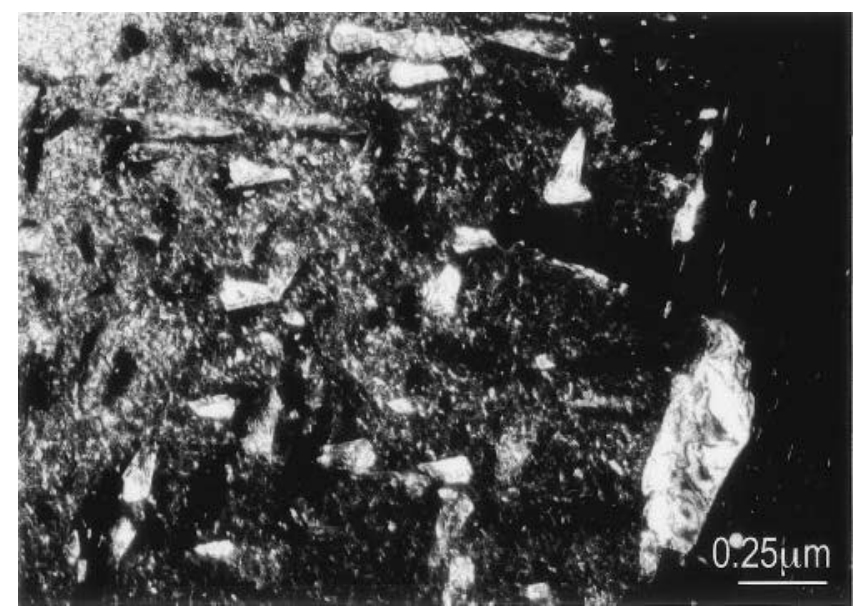

(b)

Fig. 5-(a) BF and (b) DF images of coarse and fine $\mathrm{Ni}_{3} \mathrm{Ti}$ precipitates after $3600 \mathrm{~s}$ of aging of undeformed specimen. Zone axis for (a) and (b) is $[001]_{\alpha^{\prime}}$.

Atom maps from 3DAP experiments on as-quenched samples are provided in Figure 9(a) and reveal what appears to be a random distribution of all solute atoms in the Fe matrix. A contingency table analysis was made to correlate $\mathrm{Ni}-\mathrm{Ti}$ solute-solute interactions (Table IV), and the results indicate that we must reject the null hypothesis that these species are randomly distributed. Inspection of the contingency table indicates that these species are weakly anti-clustered because there are statistically significant fewer occasions when these two elements are co-located compared to what would be expected if they were distributed randomly. Specifically, this distribution exhibits $\chi^{2}=0.02$, where $\chi_{\text {crit }}^{2}=0.8$ for $v=2$ at the 0.01 level of significance, where $\chi^{2}$ is the Chisquared value for the solute distribution, $\chi_{\text {crit }}^{2}$ is the critical value for $v$ degrees of freedom at the assumed level of significance. ${ }^{[21]}$ This situation is significantly different after aging: 3DAP analyses of samples aged at $550{ }^{\circ} \mathrm{C}$ for 5 seconds revealed the first signs of phase decomposition, with the formation of atomic co-clusters of Ni-Ti. These co-clusters are imaged directly in Figure 9(b) and these observations are supported by contingency table analysis (Table V), which reveals a preferred interaction between $\mathrm{Ni}$ and $\mathrm{Ti}$ at the 0.01 level of significance, with $\chi^{2}=21.3$, where $\chi_{\text {crit }}^{2}=16.8$ for $v=6$. The Ni-Ti co-clusters were observed to persist during further aging and were observed after 15 seconds of aging (Figure $9(\mathrm{c})$ ). The size of the Ni-Ti co-clusters was larger in the sample aged for 15 seconds than in the sample aged 5 seconds. Contingency table analysis confirmed that the degree of Ni-Ti atomic co-clustering observed after 15 seconds was more extensive with $\chi^{2}=237.4$, where $\chi_{\text {crit }}^{2}=16.8$ for $v=6$ at the 0.01 level of significance (Table VI).

\section{DISCUSSION}

\section{A. Mechanical and Microstructural Evolution during Aging of Undeformed Material}

\section{Cluster hardening}

The present results show a remarkably rapid rise in the hardness of the Fe-Ni-Ti alloy after aging for only 5 seconds at $550{ }^{\circ} \mathrm{C}$ (Figure 1). This initial increase does not appear to be accompanied by precipitation, insofar as could be observed with the TEM techniques used. Mössbauer studies ${ }^{[6]}$ have suggested that this effect might arise from the formation of Ni-Ti solute clusters. The present 3DAP studies have confirmed the presence of Ni-Ti atomic coclusters in the microstructure of samples aged for 5 seconds. The ability of clusters to hinder movement of dislocations and so strengthen alloy materials is becoming experimentally well established using 3DAP methods ${ }^{[15,22]}$ and is described by Haasan. ${ }^{[23]}$ Local changes in lattice elasticity as well as the need to cut a diffuse antiphase boundary arising from the pairing (or higher order combinations) of solute species represent the principal hindrances to dislocation motion under this mechanism. The size and extent of Ni-Ti clustering increases with aging time, as shown by the 3DAP data recorded after 15 seconds of aging (Fig. 9(c)).

\section{Early softening}

Figure 1 shows that after the rapid initial hardening, a marked softening occurs. It is significant that no precipitation was observed during the first stages of softening ( $>30$ seconds). However, Ni-Ti co-clusters remained after 15 seconds of aging, and somewhat later in the softening process, $\mathrm{Ni}_{3} \mathrm{Ti}$ precipitation was observed. It seems highly significant that the size 


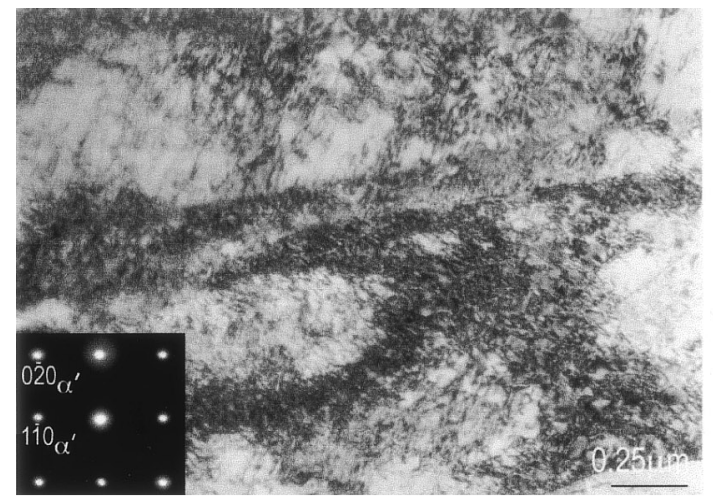

(a)

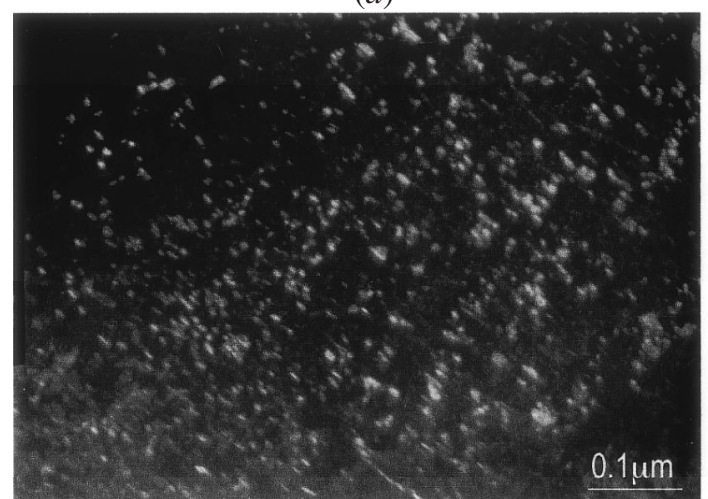

(c)

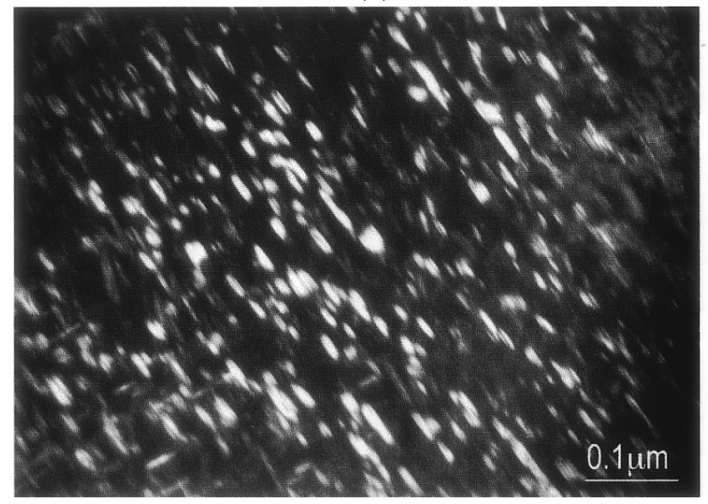

(e)

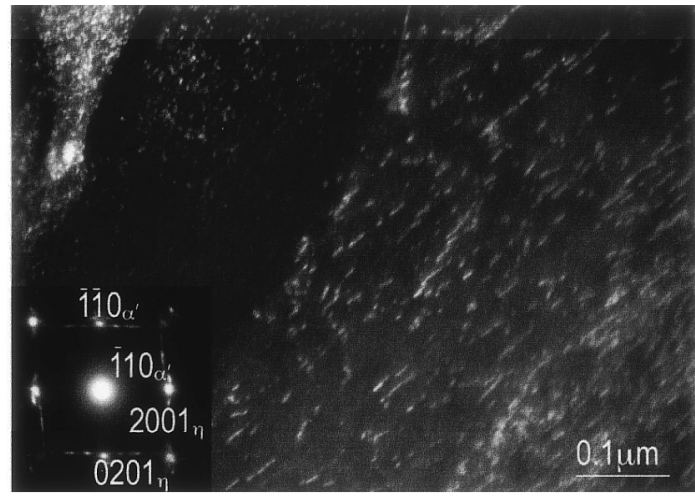

(b)

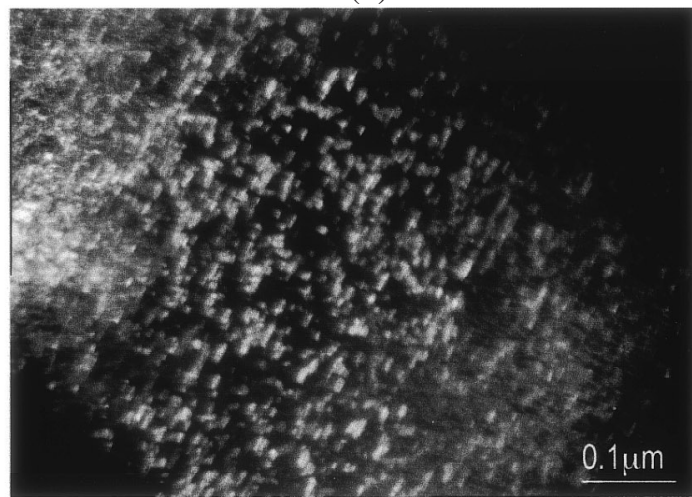

$(d)$

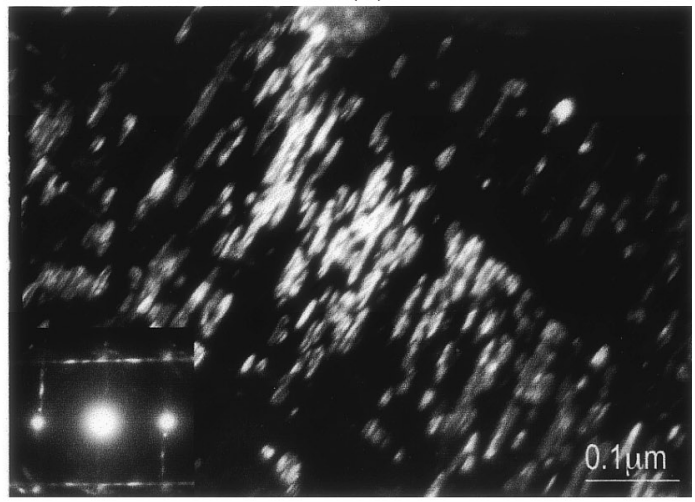

$(f)$

Fig. 6- $[001]_{\alpha^{\prime}}(a)$ BF and $(b)$ through $(g)$ DF images with corresponding SAED patterns insert for Fe-Ni-Ti alloy age-hardened 20 pct deformed Fe-NiTi alloy. The aging times presented are (a) $5 \mathrm{~s}$, (b) $10 \mathrm{~s}$, (c) $45 \mathrm{~s}$, (d) $60 \mathrm{~s}$, (e) $600 \mathrm{~s}$, and (f) $3600 \mathrm{sec}$.

and dispersion of these precipitates was insufficient to contribute substantially to the hardening and strengthening, at this stage. By analogy to counterpart phenomena in Al-base alloys, ${ }^{[15,16]}$ $\mathrm{Ni}_{3} \mathrm{Ti}$ precipitates may be heterogeneously nucleated at some of the clusters. However, the high dislocation density in martensite also supports the heterogeneous nucleation of $\mathrm{Ni}_{3} \mathrm{Ti}$ particles at dislocation intersections, jogs on dislocations, etc. Following nucleation, it is proposed that these precipitates grow and quickly consume not only the clusters at which they nucleated but all other clusters falling under their concentration shadow. ${ }^{[24,25,26]}$ Precipitates nucleated at dislocations may eventually incorporate these defects during growth.

The observed increase in austenite volume fraction from 2 to 7 pct after 15 seconds of aging and to 16 pct after 60 seconds of aging would also have contributed to the observed decrease in microhardness. A similar reversed transformation of martensite during aging was observed in $18 \mathrm{wt}$ pct Ni maraging steels ${ }^{[8]}$ and an Fe-Ni-Ti-Mn alloy. ${ }^{[27]}$ Hardening by solute co-clusters and precipitates in martensite is not sufficient to compensate for the softening introduced by the formation of reversed austenite.

Figure 2 shows no evidence of a decrease in UTS and YS after initial strengthening, in contrast to the microhardness behavior. The generalized deformation introduced during these uniaxial tests, compared to the localized plastic flow developed during microhardness testing, is thought to be responsible for the absence of UTS and YS minima in undeformed samples.

\section{Precipitate coarsening and effects upon mechanical} properties

The finding that the slope of a plot of the logarithm of the average $\mathrm{Ni}_{3} \mathrm{Ti}$ needle length $v s$ the logarithm of the aging 
time is 0.41 for undeformed specimens (Figure 8), rather than 0.33 as expected for coarsening, suggests that, when taken in conjunction with the small changes in average interparti-

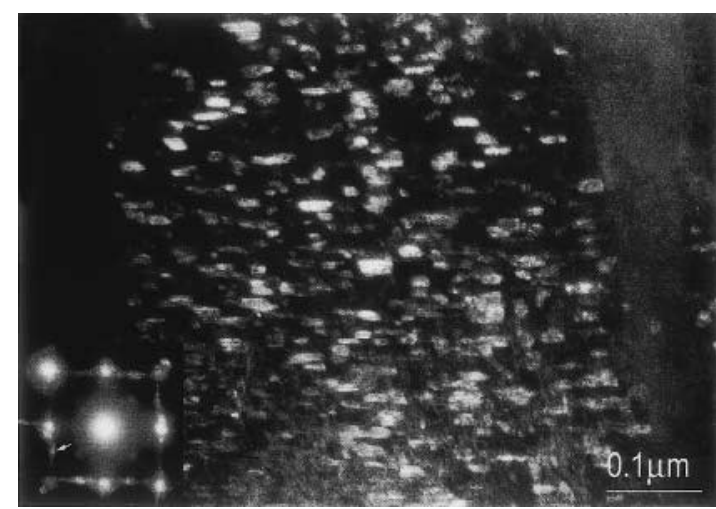

(a)

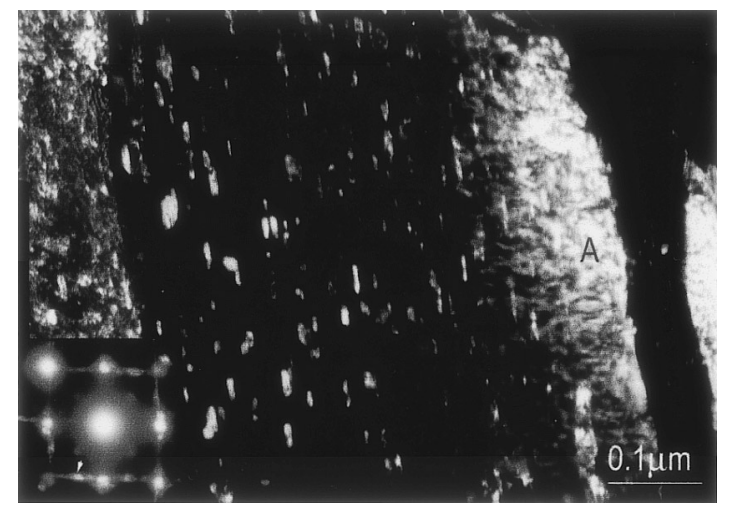

(b)

Fig. $7-[001]_{\alpha^{\prime}}$ DF images of 10 pct deformed and aged for $600 \mathrm{~s}$ at $550{ }^{\circ} \mathrm{C}$ $\mathrm{Fe}-\mathrm{Ni}$-Ti alloy showing two orientations of precipitates in martensite crystal. Arrows indicate diffraction spots from which DF images were recorded. "A" denotes reversed austenite.

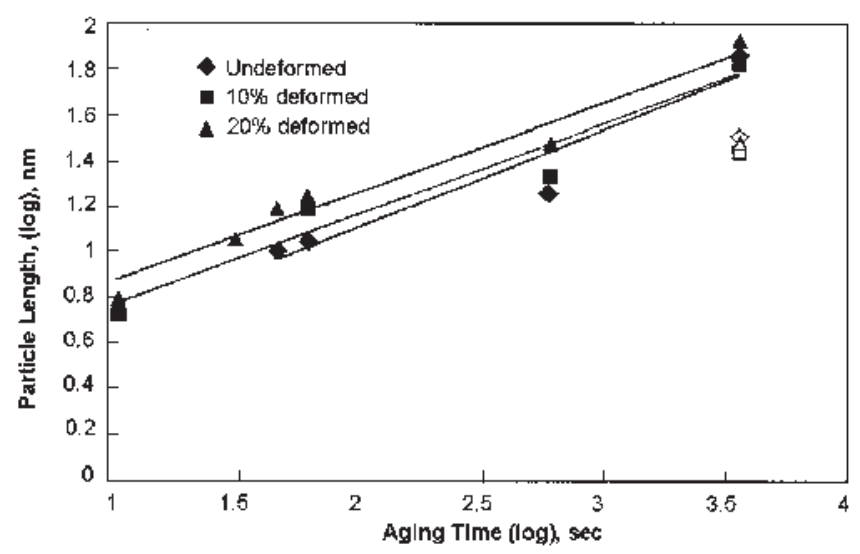

Fig. 8-Variation of the logarithm of precipitate length with the aging time. Open data points correspond to the length of fine precipitates observed after $3600 \mathrm{~s}$ of aging. cle spacing during the first 600 seconds of aging (Table II), nucleation, growth, and coarsening are overlapping processes. Increases in the aspect ratio of needle with aging time indicate that shape coarsening is occurring concurrently with size coarsening. These results are in turn consistent with the diminished hardness at aging times from $\sim 60$ to 600 seconds. As already mentioned, this hardness decrease is also caused by the significant increase in volume fraction of reversed austenite (28 pct after 600 seconds of aging and 40 pct after 3600 seconds of aging). Figures 2(a) and (b), on the other hand, show that the YS reaches a (possibly spurious) maximum at approximately 600 seconds and that the UTS is also quite high at this time. Increased dislocation tangling among the precipitates may explain why UTS continues to rise slightly at longer aging times, whereas the YS does not. The relationship between the hardness and yield strength for this steel is very complex and does not obey the usual relationship due to their low rate of work hardening and YS to UTS ratio, ${ }^{[28]}$ and therefore will not be considered in this study. Furthermore, the hardness tests provide highly localized results of the strength of the predominantly martensitic microstructure, which comprises components from the instrinsic lattice and constituent defects, cluster strengthening, and precipitate strengthening. While these effects occur in the martensite alone, the tensile properties also account for the generalized plastic flow conditions arising from a partly martensitic and partly austenitic matrix.

The decrease in ductility accompanying the hardness and strength increases is quite conventional. This effect may be accentuated by the needle morphology of the $\mathrm{Ni}_{3} \mathrm{Ti}$ precipitates. When these needles are very small (Figures 4 through 7), their tips can act as stress concentrators, reducing the ability of the surrounding matrix to deform plastically before fracture. The effect of these precipitates has surpassed the softening and ductilizing effect expected from the progressive increase in the fraction of austenite in the microstructure, formed from the reverse transformation of the martensite.

\section{Precipitation hardening and softening at longer aging times}

Although precipitation in undeformed specimens begins after aging for 45 seconds at $550{ }^{\circ} \mathrm{C}$, the large precipitates formed early in the process are evidently too widely separated to compensate for formation of reversed austenite. Such precipitates appear to nucleate at interlath boundaries, and probably preferentially formed at boundaries between martensite laths that possess the same habit plane but different habit directions, and especially at boundaries between laths parallel to different habit planes of the same form. Figure 5 indicates that the large precipitates that nucleated early can also form at high energy sites within laths. In the interiors of martensite laths, however, there are also many other potential nucleation sites with lesser potency. Among these, dislocation intersections are likely to be the most important. Jog on individual dislocations may also furnish suitable sites. Because of the low diffusivities of $\mathrm{Ni}$ and $\mathrm{Ti}$ in ferrite, ${ }^{[29]}$

Table III. Fraction of Austenite ( $\gamma$ ) Formed by Reverse Transformation from the Quenched-In Martensite

\begin{tabular}{lccccccc}
\hline Aging time $(\mathrm{sec})$ & as-quenched & 5 & 15 & 60 & 600 & 3600 & 86,400 \\
\hline Fraction of $\gamma$ & 0.02 & 0.02 & 0.07 & 0.17 & 0.28 & 0.40 & 0.55 \\
\hline
\end{tabular}




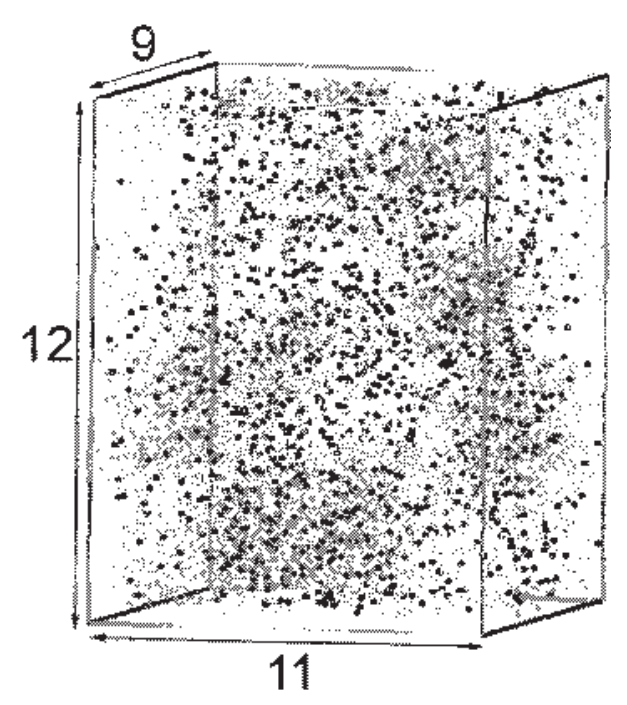

(a)

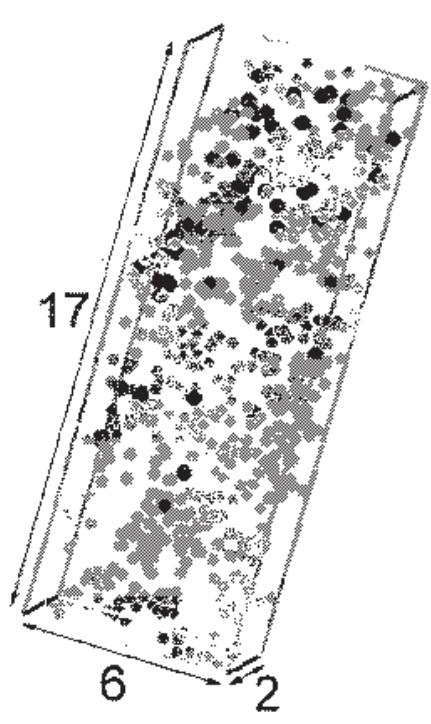

(b)

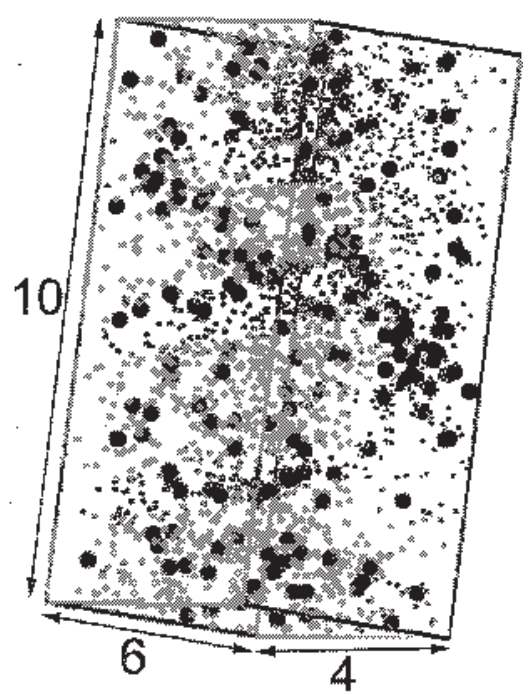

(c)

Fig. 9-A sequence of three-dimensional atom probe elemental maps showing the formation of solute clusters during the early stages of aging at $550{ }^{\circ} \mathrm{C}$ in undeformed Fe-Ni-Ti alloy: (a) as-quenched, (b) $5 \mathrm{~s}$, and $(c) 15 \mathrm{~s}$. Dimensions of the tomographic volumes are in nanometers. Clustering of Ti atoms after 5 and $15 \mathrm{~s}$ was revealed visually by careful selection of highly magnified volume elements of the probed region, such as in (b) and (c), here. The occurrence of Ni-Ti coclusters was supported by contingency table analyses (Table V ( $5 \mathrm{~s})$ and Table VI (15 s)). Gray small spots denote Ni atoms, and dark larger spots show Ti atoms.

Table IV. Contigency Tables for Co-Segregation of $\mathrm{Ni}$ and Ti in Fe-25.3Ni-1.7Ti (Weight Percent) Alloy in the As-Quenched Condition

(a) Experimental Observations, $n_{i j}$

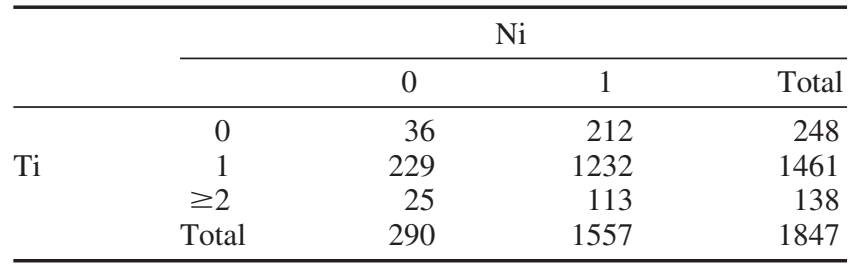

(b) Estimated Values, $e_{i j}$

\begin{tabular}{rrrrr}
\hline & \multicolumn{4}{c}{$\mathrm{Ni}$} \\
\cline { 2 - 5 } & & 0 & 1 & Total \\
\hline \multirow{3}{*}{$\mathrm{Ti}$} & 0 & 39 & 209 & 248 \\
& 1 & 229 & 1232 & 1461 \\
& $\geq 2$ & 22 & 116 & 138 \\
& Total & 290 & 1557 & 1847 \\
\hline
\end{tabular}

regions well removed from the larger precipitates can still retain much of their original supersaturation. Hence, nucleation of $\mathrm{Ni}_{3} \mathrm{Ti}$ at this array of less effective nucleation sites can be expected to begin at a later stage in the precipitation sequence, say, at about 300 seconds. Eventually, the size and the spacing between these small precipitates re-strengthens the alloy and produces the peak hardness shown in Figure 1 at 10,800 seconds. Table II shows that the spacing between these smaller particles after 3600 seconds is $3 \mathrm{~nm}$. Figure 1 indicates that when aging is extended to 86,400 seconds, coarsening is sufficiently extensive to renew softening and this occurs in conjunction with the formation of increas-
Table V. Contigency Tables for Co-Segregation of $\mathrm{Ni}$ and Ti in Fe-25.3Ni-1.7Ti (Weight Percent) Alloy after Aging at $550{ }^{\circ} \mathrm{C}$ for 5 Seconds

(a) Experimental Observations, $n_{i j}$

\begin{tabular}{rrrrrr}
\hline & \multicolumn{5}{c}{$\mathrm{Ni}$} \\
\cline { 2 - 6 } & \multicolumn{1}{c}{0} & 1 & 2 & Total \\
\hline \multirow{3}{*}{$\mathrm{Ti}$} & 0 & 317 & 1135 & 0 & 1452 \\
& 1 & 1881 & 8246 & 1 & 10,128 \\
& 2 & 228 & 1207 & 1 & 1436 \\
& $\geq 3$ & 0 & 5 & 0 & 5 \\
& Total & 2426 & 10,593 & 2 & 13,021 \\
\hline
\end{tabular}

(b) Estimated Values, $e_{i j}$

\begin{tabular}{rrrrrr}
\hline & \multicolumn{5}{c}{$\mathrm{Ni}$} \\
\cline { 2 - 6 } & & 0 & 1 & 2 & Total \\
\hline \multirow{3}{*}{$\mathrm{Ti}$} & 0 & 271 & 1181 & 0 & 1452 \\
& 1 & 1887 & 8239 & 2 & 10,128 \\
& 2 & 268 & 1168 & 0 & 1436 \\
& $\geq 3$ & 1 & 4 & 0 & 5 \\
& Total & 2426 & 10,593 & 2 & 13,021 \\
\hline
\end{tabular}

ing amounts of reversed austenite (up to $55 \mathrm{pct}$ ) at later aging times.

\section{B. Effect of Deformation on Aging Behavior of $\mathrm{Fe}-\mathrm{Ni}$-Ti Steel}

\section{Cluster hardening}

Figure 1 reveals a higher increment in hardness after 5 seconds of aging in deformed samples compared to those undeformed. This increment is larger in samples aged after $20 \mathrm{pct}$ deformation. Figure 2 indicates that there are similar differences 
Table VI. Contingency Tables for Co-Segregation of $\mathrm{Ni}$ and Ti in Fe-25.3Ni-1.7Ti (Weight Percent) Alloy after Aging at $550{ }^{\circ} \mathrm{C}$ for 15 Seconds

(a) Experimental Observations, $n_{i j}$

\begin{tabular}{rrrrrr}
\hline & \multicolumn{5}{c}{$\mathrm{Ni}$} \\
\cline { 2 - 6 } & & 0 & 1 & 2 & Total \\
\hline \multirow{3}{*}{$\mathrm{Ti}$} & 0 & 119 & 297 & 0 & 416 \\
& 1 & 463 & 1400 & 3 & 1866 \\
& 2 & 38 & 197 & 10 & 245 \\
& $\geq 3$ & 0 & 2 & 2 & 4 \\
& Total & 620 & 1896 & 15 & 2531 \\
\hline
\end{tabular}

(b) Estimated Values, $e_{i j}$

\begin{tabular}{rrrrrr}
\hline & \multicolumn{5}{c}{$\mathrm{Ni}$} \\
\cline { 2 - 6 } & & 0 & 1 & 2 & Total \\
\hline \multirow{3}{*}{$\mathrm{Ti}$} & 0 & 102 & 312 & 2 & 416 \\
& 1 & 457 & 1398 & 11 & 1866 \\
& 2 & 60 & 184 & 1 & 245 \\
& $\geq 3$ & 1 & 3 & 0 & 4 \\
& Total & 620 & 1896 & 15 & 2531 \\
\hline
\end{tabular}

with respect to the UTS and YS in samples aged after deformation as have already been described for the undeformed materials. Although the dislocation density of lath martensite is high in undeformed material, the plastic deformation during cold rolling led to a further increase in dislocation density after 10 pct deformation and even further after 20 pct deformation. It is proposed that the more rapid initial hardening in the deformed materials arises because more dislocations interact among themselves and with the solute clusters. The increased dislocation density will also assist a more rapid formation of solute clusters by accelerating mass transport.

\section{Early softening reduction}

The hardness minimum followed the initial rapid hardening is largely eliminated in specimens deformed 10 pct prior to aging and is converted into an initial plateau in 20 pct deformed specimens. Anomalously, UTS (Figure 2(a)) but not YS (Figure 2(b)) undergoes a significant decrease at 10 seconds of aging time. In the case of undeformed specimens, precipitates were first seen after aging for 45 seconds whereas after 10 and 20 pct deformation, they appeared after aging for only $10 \mathrm{sec}-$ onds. Their size was also much smaller ( $\sim 6-\mathrm{nm}$ length) and their number density was higher (7-nm interparticle distance) relative to precipitates in undeformed alloys (Table II). Accelerated diffusion of solute from the $\alpha^{\prime}$ matrix along dislocation lines to the precipitates should also increase their growth kinetics. However, Figure 8 shows that after aging for 10 seconds, when precipitates were first observed in deformed specimens, there is only a slight difference between the particle size observed in samples aged after 10 pct deformation and the samples aged after 20 pct deformation. Increased competition for solute resulting from more rapid nucleation rates expected in the 20 pct deformed specimens may be responsible for the similarity of precipitate sizes in the two sets of specimens.

\section{Precipitation strengthening}

Although the formation of precipitates in deformed material was noticed after 10 seconds of aging time, the accumulation of sufficient precipitates to provide an increase in hardness and compensate for the increased amount of reversed austenite was attained only between the aging times of 30 and 45 seconds (Figure 6(c), Table II). There was no change in particle aspect ratio for aging up to 45 seconds, indicating both particle growth and slow shape coarsening during this stage (Table II). The secondary microhardness rise commences as early as 30 seconds in samples aged after 20 pct deformation, compared to 600 and 300 seconds in undeformed samples and those aged after 10 pct deformation, respectively. The secondary peaks in microhardness, UTS, and YS are also reached sooner in deformed specimens (at 600 seconds). This more rapid precipitation-hardening response in deformed samples is explained by the higher number of favorable nucleation sites, e.g., dislocation intersections, jogs on dislocations, etc. ${ }^{[30]}$ per unit volume of matrix.

At most aging times, the precipitate size in the samples aged after 20 pct deformation is coarser compared to those aged after 10 pct deformation, suggesting a higher precipitate growth rate during the early stages of aging in these samples (Figure 8). Table II clearly shows that in 20 pct deformed specimens, size coarsening begins at between 10 and $30 \mathrm{sec}-$ onds and continues throughout the aging cycle. Shape coarsening, usually a considerably slower process because of the smaller driving force involved, does not begin until between 30 and 45 seconds. In undeformed specimens, Table II demonstrates that both size and shape coarsening are slower, even though the latter appears to take place more rapidly than the former in this situation.

\section{Precipitation hardening and softening at longer aging times}

As indicated in the counterpart subsection for undeformed specimens, at late aging times, hardness becomes the resultant of softening by both mechanisms: (1) the coarsening of large precipitates $v s$ formation of additional small precipitates at less potent nucleation sites and (2) formation of a large amount of reversed austenite. The data in Table II suggest that the coarsening of the large precipitates, accelerated by diffusion along dislocations, outweighs the additional nucleation of fine precipitates in the 20 pct deformed specimens. These two factors appear to be better balanced in undeformed specimens. With a significant volume fraction of austenite present in the microstructure ( $\sim 55 \mathrm{pct})$, it might be concluded that softening would be due predominantly to the change in martensite/austenite ratio.

Both UTS and YS follow the trend for hardness and decrease significantly at aging times that exceed 600 seconds. However, both UTS and YS decline much more rapidly than hardness. The slight increase in the ductility is proposed to result from the increased volume fraction of austenite.

\section{SUMMARY}

The evolution of the clustering, precipitation hardening sequences during the aging of an Fe-25.3Ni-1.7Ti (wt pct) alloy at $550{ }^{\circ} \mathrm{C}$ is a multistep process. This aging sequence was studied in undeformed specimens as well as in those deformed 10 and 20 pct prior to aging. Microhardness measurement was the main tool used to investigate the effects of aging upon mechanical properties, though supplementary studies were made on YS, UTS, and the RA using shear punch testing. 
The first evidence of phase decomposition in the undeformed samples is the formation of a high density of Ni-Ti clusters, observed after only 5 seconds of aging at $550{ }^{\circ} \mathrm{C}$. It is proposed that these clusters exert a strengthening effect arising from the extra energy required for dislocations to cut through the favorable solute-solute bonds that are established during the clustering process. This produces a marked increase in hardness. Subsequently, an increased amount of reversed austenite is formed by the transformation of martensite. At the same time, the clusters grow and become more dispersed with the implication that less preferentially formed solute-solute pairs will be formed across the slip plane. These effects result in a decrease in hardness that is only partly compensated by the hardening associated with the precipitation of $\mathrm{Ni}_{3} \mathrm{Ti}$. These precipitates, later becoming quite coarse, are evidently nucleated at high energy sites, such as clusters or intersections of dislocations. Such precipitation leads to peak hardness. Eventually, overaging occurs with $\mathrm{Ni}_{3} \mathrm{Ti}$ precipitates growing coarser and the distance between them increasing. This is accompanied by significant increases in the volume fraction of reversed austenite and results in a hardness and strength decrease.

When specimens are deformed 10 or 20 pct by rolling prior to aging, the hardening response after 5 seconds of aging is increased as a result of more extensive interactions between dislocations and solute clusters as well as increased dislocation-dislocation interaction. The postclustering decline in hardness is reduced or eliminated, respectively, by the earlier onset of $\mathrm{Ni}_{3} \mathrm{Ti}$ precipitation. The accelerated nucleation of fine $\mathrm{Ni}_{3} \mathrm{Ti}$ precipitates on the additional nucleation sites provided by prior deformation helps to mitigate against precipitate coarsening and the effects of reversed transformation of martensite to austenite during the intermediate stages of aging. After prolonged aging, an accelerated coarsening and softening reaction is observed.

Both YS and UTS are increased significantly by the rapid formation of $\mathrm{Ni}-\mathrm{Ti}$ solute co-clusters, particularly in deformed specimens. At later stages of aging, however, these mechanical properties are less sensitive to clustering and precipitation processes, but are controlled by the contribution from both phases present in the microstructure: agehardened martensite and reversed austenite. The overall effect of prior deformation is to improve significantly both of these properties.

\section{ACKNOWLEDGMENTS}

This work has been supported by the Australian Research Council. The authors thank Dr. R.V. Televich, the Institute for Metal Physics, National Academy of Sciences, Ukraine, for providing material for this research. The facilities and scientific and technical assistance from the staff in the NANO Major National Research Facility at the Electron Microscope Unit, the University of Sydney, in conducting HRTEM stud- ies are gratefully appreciated. Support from the ORNL ShaRE Program in carrying out 3DAP tests is gratefully acknowledged.

\section{REFERENCES}

1. G.P. Miller and W.I. Mitchell: J. Iron Steel Inst., 1965, vol. 203, pp. 899-904.

2. M.D. Perkas and V.M. Kardonskii: High Strength Maraging Steels, Metallurgiya, Moscow, 1970.

3. E.V. Emchenko-Rybko, S.P. Oshkaderov, R.V. Televich, and G. Ziss: Phys. Met., 1985, vol. 6, pp. 495-502.

4. E.V. Emchenko-Rybko, S.P. Oshkaderov, and R.V. Televich: Phys. Met., 1985, vol. 5, pp. 1119-25.

5. V.M. Schastlivtcev, Yu. V. Kaletina, I.L. Yakovleva and V.D. Sadovskiy: Phys. Met. Metall., 1986, vol. 62, pp. 150-158.

6. V.G. Gavrilyuk, E.V. Emchenko-Rybko, V.M. Nadutov, S.P. Oshkaderov, and R.V. Televich: Phys. Met., 1990, vol. 9, pp. 191-98.

7. V.M. Schastlivtsev, A.I. Uvarov, Ye.I. Anufrieva, I.L. Yakovleva, M.S. Khadyyev, and A.A. Kruglov: Phys. Met. Metallov., 1991, vol. 72, pp. 186-93.

8. V.K. Vasudevan, S.J. Kim, and C.M. Wayman: Metall. Trans. A, 1990, vol. 21A, pp. 2655-68.

9. J.M. Burgers: Physica, 1934, vol. 1, p. 561.

10. A. Cerezo, C.R.M. Grovenor, M.C. Hetherington, W. Sha, B.A. Shollack, and G.D.W. Smith: Mater. Characterization, 1990, vol. 25, pp. 143-56.

11. W. Sha, A. Cerezo and G.D.W Smith: Scripta Metall., 1992, vol. 26, pp. 517-22 and 526-28.

12. R.D. Garwood and R.D. Jones: J. Iron Steel Inst., 1966, vol. 204, p. 512.

13. R.K. Pitler and G.S. Ansell: Trans. ASM, 1964, vol. 57, p. 220.

14. W. Sha, A. Cerezo and G.D.W. Smith: Metall. Mater. Trans. A, 1993, vol. 24A, pp. 1221-56.

15. S.P. Ringer and K. Hono: Mater. Characterization, 2000, vol. 44, pp. 101-31.

16. J.F. Nie, B.C. Muddle, H.I. Aaronson, S.P. Ringer, and J.P. Hirth: Metall. Mater. Trans. A, 2002, vol. 33A, p. 1649.

17. N.A. Gjostein: Diffusion, ASM, Metals Park, OH, 1973, p. 241.

18. G.E. Dieter: Mechanical Metallurgy, McGraw-Hill, New York, NY, 1988, pp. 191 and 329.

19. G.E. Lucas, G.R. Odette, and J.W. Shekherd: The Use of Small-Scale Specimens for Testing Irradiated Material, ASTM STP 488, ASTM, Philadelphia, PA, 1986, pp. 112-140.

20. B.D. Cullity: Elements of X-ray Diffraction, Addision-Wesley Publishing Co. Inc., New York, NY, 1978, pp. 508-10.

21. M.K. Miller, A. Cerezo, M.G. Hetherington, and G.D.W. Smith: Atom Probe Field Ion Microscopy, Oxford University Press, Oxford, United Kingdom, 1996.

22. M. Maruyama, K. Hono, M. Saga, and M. Kikuchi: Mater. Sci. Eng. A, 1998, vol. 250A, pp. 127-32.

23. P. Haasan: in Physical Metallurgy, 4th ed., R.W. Cahn and P. Haasan, eds., Amsterdam, North Holland, 1996, vol. 3, p. 2024.

24. C. Laird and H.I. Aaronson: Acta Metall., 1966, vol. 14, pp. 171.

25. M.F. Chisholm and D.E. Laughlin: in Phase Transformations '87, G.W. Lorimer, ed., IOM, London, 1988, p. 1.

26. J.B. Cohen: Metall. Trans. A, 1992, vol. 23A, p. 2685.

27. S.-J. Kim and C.M. Wayman: Mater. Sci. Eng. A, 1990, vol. A128, pp. 217-30.

28. J.W. Martin: Micromechanisms in Particle Hardened Alloys, Cambridge University Press, Cambridge, United Kingdom, 1980, pp. 53-60.

29. J. Fridberg, L.-E. Torndahl, and M. Hillert: Jern. Ann., 1969, vol. 153, p. 263.

30. R.B. Nicholson: Phase Transformations, ASM, Metals Park, OH, 1970, p. 269. 